\title{
AS CONTRIBUIÇÕES DO EMPREENDEDORISMO CORPORATIVO À IMPLEMENTAÇÃO DE ESTRATÉGIAS
}

\section{RESUMO}

O processo de implementação da estratégia nas organizações, como indicam algumas pesquisas, raramente obtém êxito superior a 20\%, o que aponta para a existência de um gap entre o que se planeja e o que efetivamente se executa. O objetivo deste ensaio teórico é estabelecer conexão entre dois dos temas mais tratados do campo da estratégia, sustentando soluções aos problemas da implementação da estratégia pelo emprego do empreendedorismo corporativo. Como resultado, são apresentadas seis proposições que apontam o empreendedorismo corporativo como uma solução viável para alguns dos principais problemas à Implementação como a tradução inadequada da estratégia e da visão, comunicação ineficaz da estratégia, falta de comprometimento, atuação e competência da liderança, e sistema de poder e status quo da cultura organizacional. Delineamentos futuros indicam a investigação empírica das proposições sugeridas.

Palavras-chave: Empreendedorismo; Empreendedorismo Corporativo; Implementação de Estratégias; Execução de Estratégias; Barreiras.

\section{THE CONTRIBUITIONS OF CORPORATIVE ENTREPRENEURSHIP TO THE IMPLEMENTATION OF STRATEGIES}

\begin{abstract}
The process of implementation of strategy in organizations, as pointed by some researches, rarely achieve an outcome above $20 \%$, which suggests the existence of a gap between what is planned and what effectively is carried out. The aim of this essay is to establish a connection between two of the most used subjects on the strategy field, supporting solutions to the problems of the implementation of strategy through the employment of corporative entrepreneurship. As result, six propositions are presented that point to the corporative entrepreneurship as a viable solution to some of the main problems to the implementation: an unsuitable translation of the strategy and vision, inefficient communication of strategy, lack of commitment, performance and leadership competence, and finally, power system and status quo of the cultural organization. Future sketches indicate the empiric investigation of suggested proposals.
\end{abstract}

Keywords: Entrepreneurship; Corporative Entrepreneurship; Implementation of strategies; Strategy execution; Obstacles. 
As Contribuições do Empreendedorismo Corporativo à Implementação de Estratégias

\section{LOS APORTES DE LA APLICACIÓN DE EMPRENDIMIENTO ESTRATEGIAS EMPRESARIALES}

\section{RESUMEN}

El proceso de implementación de la estrategia en las organizaciones, como muestran algunas investigaciones, rara vez consigue el éxito más del 20\%, lo que apunta a la existencia de una brecha entre lo planeado y lo que se ejecuta con eficacia. El objetivo de este ensayo teórico es establecer la conexión entre dos de los temas tratados en el campo de la estrategia, reclamando soluciones a los problemas de la aplicación de la estrategia en el empleo el emprendimiento empresarial. Como resultado, presenta seis propuestas que vinculan la iniciativa empresarial corporativa como una solución viable para algunos de los principales problemas para la aplicación como la traducción inadecuada de la estrategia y la visión, la estrategia de comunicación efectiva, la falta de compromiso, el rendimiento y la competencia de liderazgo, y el sistema poder y el estatus quo de la cultura organizacional. Diseños futuros indican la investigación empírica de las propuestas sugeridas.

Palabras clave: Emprendimiento; Emprendimiento Corporativo; Aplicación de la Estrategia; Estrategias de aplicación; Barreras.

1 Mestre em Administração pela Universidade do Vale do Rio dos Sinos - UNISINOS. Brasil. E-mail: danielrgestao@hotmail.com

${ }^{2}$ Ph.D. em Management pela Clemson University, Carolina do Sul, EUA. professor do programa de pós-graduação em Administração da Universidade do Vale do Rio dos Sinos - UNISINOS. Brasil. E-mail: teixeira.rafa@gmail.com 


\section{INTRODUÇÃO}

Tem sido destaque na literatura contemporânea discussões a respeito dos processos de formulação e implementação de estratégias. Pesquisadores tem procurado identificar fatores e determinar etapas que balizam os gestores na construção de moldes para obtenção de vantagens competitivas.

Apesar de serem temas muito próximos e ligados à estratégia, são estabelecidas diferenças conceituais entre os dois assuntos. Enquanto o processo de formulação da estratégia foca em o que a empresa pode fazer de melhor para enfrentar a competitividade do ambiente no qual ela está inserida, o processo de implementação da estratégia muda o foco da pergunta para o que a organização precisa fazer para ter sucesso com uma estratégia já determinada (BOWER, 1982). No trabalho de Mintzberg e Waters (1985), a estratégia é concebida em termos de planos para o futuro (formulação), o qual leva a um sistema planejado de objetivos de longo prazo e planos de ação (implementação) a serem conduzidos pela organização. Hrebiniak (2005) é mais enfático em relação a essa diferença, e considera que a formulação e implementação podem ser diferenciadas e discutidas separadamente tanto conceitualmente como na prática.

Desafios constantes são impostos aos gestores e estudiosos em administração, em relação à execução das estratégias. Pesquisas demonstram que, apenas 10 a $20 \%$ das estratégias formuladas têm sido efetivamente implementadas e executadas com êxito nas organizações (KAPLAN, NORTON, 1997). O estudo realizado por Johnson (2004), aponta que $66 \%$ das estratégias corporativas nunca são implementadas. Alguns fatores podem ser atribuídos a esses resultados, como as limitações de recursos, limitações da visão estratégica, limitações gerenciais e limitações humanas (ATKINSON, 2006; BEER, EISENSTAT, 2000; KAPLAN, NORTON, 1997; KIM, MAUBORGNE, 2005; MANKINS, STEELE, 2005).

A crescente dificuldade das organizações associada à implementação das estratégias e a busca por maior agilidade e flexibilidade, principalmente, em um contexto de descontínuas mudanças e competitividade acirrada, é o primeiro de dois fatores que motivaram este trabalho. $O$ segundo fator, indutivamente, é apontado como uma solução ao primeiro e desfruta, também, de bastante notoriedade no meio acadêmico: o empreendedorismo corporativo.

Em relação ao empreendedorismo, desde 1947, em Harvard nos Estados Unidos, onde o ensino do tema teve procedência, nunca o termo desfrutou de tanta notoriedade, sendo extensivamente usado nos estudos de Economia, Sociologia Econômica e Administração de Empresas. Somente no país supra citado, há mais de 40 journals acadêmicos sobre o tema (FERREIRA, 2011). O estudo vem tomando força nos últimos anos, em parte, ao se apresentar como uma resposta ao desemprego, que é fruto de mudanças no cenário econômico das organizações, constantemente pressionadas a reduzir seus custos e aumentar sua competitividade (GUEDES, 2009). Além disso, o empreendedorismo também ganhou relevância devido à necessidade de as pessoas e organizações se adaptarem a um ambiente competitivo e em constante mudança. A literatura econômica e administrativa sugere que, para mercados operarem dentro de sua máxima eficiência, existe uma demanda significativa pela atividade empreendedora (LANA, 2011).

Derivado do empreendedorismo, o empreendedorismo corporativo (ou intraempreendedorismo) pode ser resumidamente conceituado como o empreendedorismo dentro de empresas existentes (ANTONCIC, HISRICH, 2001). O tema, que desfruta de um status conceitual relativamente novo, tem fixação também na escola schumpeteriana: "chamamos de empresários não apenas o homem de negócios 'independente' em sua economia de trocas, mas todos os que de fato preenchem a função pela qual definimos o conceito, mesmo que sejam funcionários dependentes, empregados 'dependentes' de uma companhia (SCHUMPETER, 1982)". Empreender corporativamente é o processo de identificação e desenvolvimento de oportunidades para criação de valor por meio da inovação (ANTONCIC, HISRICH, 2001). Intraempreendedorismo indica um bom caminho para as grandes empresas em sua busca por maior agilidade e flexibilidade, ou seja, por maior competitividade (LANA, 2011). Significa ainda, desenvolver novas tecnologias, técnicas administrativas, estratégias e até mesmo posturas competitivas (ANTONCIC, HISRICH, 2001), constituindo-se em uma alternativa viável para nutrir e desenvolver vantagens competitivas (KURATKO et. al., 2014).

Os esforços deste trabalho irão delimitar-se ao estudo do empreendedorismo dentro das organizações, ou seja, ao empreendedorismo corporativo, ora chamado de Intraempreendedorismo. Considera-se para este trabalho não haver diferença conceitual entre ambos, como tratado de igual modo pela literatura pesquisada.

O objetivo deste ensaio teórico é estabelecer conexão entre a implementação da estratégia e o empreendedorismo corporativo, buscando propor soluções aos problemas associados à implementação. Mais especificamente, esse trabalho procura responder ao seguinte problema de pesquisa: como as características do empreendedor corporativo podem contribuir para reduzir os problemas de implantação estratégica? Para isso, o estudo faz um mapeamento sobre as principais barreiras à implementação descritas na literatura. Além disso, descreve as características do empreendedor, que servem de base para estabelecer uma relação entre o empreendedor corporativo e as barreiras para implementação da estratégia. 
As Contribuições do Empreendedorismo Corporativo à Implementação de Estratégias

Este estudo e as proposições sugeridas limitar-se-ão ao processo de implementação da estratégia, sem considerar a formulação. Isso não significa dizer, no entanto, que recomenda-se que estes dois processos devem ser discutidos separadamente, como defendido por alguns na literatura, é apenas uma questão de delimitação de foco. Este trabalho tem o intuito de ser inovador em duas frentes: (1) estabelece conexão entre dois dos temas mais tratados no campo da estratégia (implementação da estratégia e empreendedorismo) e, (2) indica uma possível solução ao problema de implementação das estratégias.

\section{METODOLOGIA}

Esta investigação tem a característica de um ensaio teórico, ou seja, consiste em uma exposição lógica e reflexiva com alto nível de interpretação e julgamento pessoal (SEVERINO, 2000). A maior ênfase do aspecto crítico do trabalho repousará nas proposições sugeridas, como resposta aos questionamentos propostos e ao objetivo maior estabelecido, conectando os dois temas pilares do artigo.

A pesquisa não prevê aplicação prática, o que a classifica quanto à sua natureza como pesquisa básica. Segundo Gil (1991) isso significa dizer que ela envolve verdades e interesses universais e visa gerar conhecimentos novos úteis para o avanço da ciência. Em relação à abordagem do problema, será empregada a pesquisa qualitativa. Este tipo de atribuição não requer o uso de métodos e técnicas estatísticas, é descritiva e o pesquisador tende a analisar seus dados indutivamente (GODOY, 1995).

Referente aos procedimentos técnicos, este trabalho será desenvolvido a partir de material já publicado, constituído principalmente de artigos de periódicos, buscado na base de dados EbscoHost, e livros, caracterizando uma pesquisa bibliográfica.

Reafirma-se que o campo de estudo sobre implementação da estratégia é relativamente novo e alvo de um número crescente de trabalhos. Estudiosos de renome como Michael Porter, Coimbatore K. Prahalad, Gary Hammel e Henry Mintzberg, é válido ressaltar, tem suas pesquisas e construções teóricas vinculadas mais estreitamente ao processo de formulação da estratégia.

Como o objetivo deste estudo é estabelecer conexão entre dois temas, empreendedorismo corporativo e implementação de estratégias, buscando soluções às dificuldades da implementação, buscar-seá: (1) identificar os principais problemas encontrados pelas organizações para um eficiente e eficaz processo de execução das estratégias, (2) descrever as características do empreendedorismo corporativo e, (3) verificar a existência ou não de suporte teórico que o sustente como uma possível solução.

\section{IMPLEMENTAÇÃO DA ESTRATÉGIA: A IMPORTÂNCIA DO LÍDER}

Segundo Zagotta e Robinson (2002), não interessa quão boa e brilhante é a estratégia da organização, caso não seja possível fazer com que ela aconteça. Ao passo de que a explicação apresentada pelos autores denote ser, aparentemente, carregada de lógica e simplicidade, ela é muito contundente. $\mathrm{Na}$ busca pela vantagem competitiva, um dos principais desafios impostos focaliza-se no processo de implementação da estratégia.

A necessidade de contínua adaptação e redefinição de rumos frente ao ambiente competitivo, encontrará nas organizações que estiverem executando bem os seus planos, uma probabilidade maior de êxito (BOSSIDY, CHARAN, 2004). A dificuldade em obter, na prática, os resultados delineados no processo de definição de objetivos e estratégias, aponta para a existência de um gap entre o que se planeja e o que efetivamente se executa.

Bossidy e Charan (2004) destacam que a diferença entre uma empresa e sua concorrente é cada vez mais a habilidade de executar. Se os concorrentes estão executando os planos de forma mais eficaz, os reflexos da derrota são sentidos imediatamente: os mercados financeiros não irão esperar o desenrolar de uma complexa estratégia adota pela organização. Por isso, os líderes que não conseguem executar não costumam ter uma segunda chance.

As lideranças executivas podem ser capacitadas e habilidosas para desenvolvimento das estratégias, mas encontram dificuldades e poucas alcançam um elevado grau de sucesso na colocação desses planos em movimento com uma efetiva execução das ações planejadas (HREBINIAK, 2005). É necessário, portanto, que os líderes pratiquem a disciplina da execução em todos os níveis hierárquicos, devendo fazer parte da estratégia e das metas da empresa, sendo este considerado um de seus mais importantes papéis (BOSSIDY, CHARAN, 2004). A competência na execução e implementação da estratégia é o teste decisivo para a liderança. Liderança sem disciplina da execução é incompleta e ineficaz. Sem a habilidade para fazer as coisas acontecerem, todos os outros atributos da liderança tornam-se inoperantes (FAULL \& FLEMING, 2005).

O comprometimento do líder de "corpo e alma", é fundamental para a execução dos planos em uma organização. Liderar é muito mais do que pensar alto ou conversar informalmente com os investidores e com os legisladores, requer um entendimento e um envolvimento pessoal profundo com o negócio, com amplo conhecimento do seu pessoal e do seu ambiente. É envolver-se diretamente participando de forma ativa e efetiva nas decisões que tenham impacto relevante na execução da estratégia (BOSSIDY, CHARAN, 2004). 


\section{IMPLEMENTAÇÃO DA ESTRATÉGIA: BARREIRAS}

Como já destacado, são recentes os estudos que focam na investigação do processo de implementação das estratégias. No universo das pesquisas acadêmicas a atenção maior, até então, fixou-se no processo de formulação das estratégias e nas razões que explicam a vantagem competitiva das organizações. Trabalhos já efetuados sobre o tema apontam que somente $10 \%$ das estratégias formuladas chegam a ser implementadas (MINTZBERG, 2000; KENNY, 2006). Em se tratando de estratégias de nível corporativo, este índice pode chegar a $66 \%$, segundo o estudo de Johnson (2004). Essa diferença entre o que se obtém como resultado e os planos traçados previamente denotam para existência de um grande um buraco, ou gap organizacional. $\mathrm{O}$ processo de implementação, portanto, é considerado, atualmente, um dos principais desafios das organizações em busca de uma vantagem comparativa em relação aos concorrentes (THAIN, 1990).

Com o objetivo de descrever visualmente os frutos da investigação sobre os conjuntos de barreiras disponíveis na literatura, foi desenvolvido o Quadro 1. Preservando o motivo raiz apontado por cada autor, foram identificados os principais obstáculos à implementação, sendo os resultados, sintetizados, agrupados e distribuídos. É válido destacar que a pesquisa delimitou-se ao estudo dos conjuntos de barreiras, não atendo-se, de forma específica e aprofundada, a um tipo ou outro de barreira identificada.

Dentre as barreiras mais observadas, em ordem decrescente, estão a falta de comprometimento, atuação ou habilidades das lideranças durante o processo de implementação (MANKINS, STEELE, 2005; DEVLIN, 1989; KIM, MAUBORGNE, 2005; ATKINSON, 2006; HREBINIAK, 2005; BEER, EISENSTAT, 2000). A atuação das lideranças pode ser considerada um pressuposto fundamental ao processo, já que exercem um papel protagonista como agente de mudanças e detém, formal ou informalmente, a responsabilidade de colocar os planos em movimento, executando ações determinadas. Tanto a habilidade como o comprometimento do líder são fatores que caminham juntos e, possuir apenas um ou outro, também implica em dificuldades. 


\begin{tabular}{|c|c|c|c|c|c|c|c|c|}
\hline Barreiras & $\begin{array}{l}\text { Mankins e } \\
\text { Ste ele (2005) }\end{array}$ & $\begin{array}{c}\text { Zagotta e } \\
\text { Robins on } \\
(2002)\end{array}$ & $\begin{array}{l}\text { Devlin } \\
(1989)\end{array}$ & $\begin{array}{c}\text { Kaplan e } \\
\text { Norton } \\
\text { (1997) }\end{array}$ & \begin{tabular}{|c|} 
Kim e \\
Mauborgne \\
$(2005)$
\end{tabular} & $\begin{array}{c}\text { Atkinson } \\
(2006)\end{array}$ & $\begin{array}{c}\text { Hrebiniak } \\
(2005)\end{array}$ & $\begin{array}{c}\text { Beer e } \\
\text { Eisenstat } \\
(2000)\end{array}$ \\
\hline Alocação de Recursos (ina de quação ou indisponibilidade) & $\mathrm{X}$ & & $\mathrm{x}$ & $\mathrm{x}$ & $\mathrm{x}$ & & $\mathrm{x}$ & \\
\hline Comunicação (ineficaz ou ina dequa da) & $\mathrm{x}$ & $\mathrm{x}$ & $\mathrm{x}$ & & & $\mathrm{x}$ & $\mathrm{x}$ & $\mathrm{x}$ \\
\hline Coordenação, ações de execução (indefinidas) & $\mathrm{x}$ & & & & & $\mathrm{x}$ & & $\mathrm{x}$ \\
\hline Acc ountability (in definição) & $\mathrm{x}$ & & & & & & & \\
\hline Cultura organizacional (sistema de poder, status quo) & $\mathrm{x}$ & & $\mathrm{x}$ & & $\mathrm{x}$ & & $\mathrm{x}$ & \\
\hline $\begin{array}{l}\text { Sistemas de monitoramento (aus ência, deficiência, } \\
\text { inadequação) }\end{array}$ & $\mathrm{x}$ & $\mathrm{x}$ & $\mathrm{x}$ & $\mathrm{x}$ & & $\mathrm{x}$ & $\mathrm{x}$ & \\
\hline Lideranças (comprometimento, atuação, habilida des) & $\mathrm{x}$ & & $\mathrm{x}$ & & $\mathrm{x}$ & $\mathrm{x}$ & $\mathrm{x}$ & $\mathrm{x}$ \\
\hline $\begin{array}{l}\text { A linhamento (competência organizacional, estrutura } \\
\text { organizacional, requerimentos da estraté gia) }\end{array}$ & $\mathrm{x}$ & & $\mathrm{x}$ & & $\mathrm{x}$ & & & $\mathrm{x}$ \\
\hline Visão, Objetivos (vinculação, quantificação) & & $\mathrm{x}$ & & $\mathrm{x}$ & & $\mathrm{x}$ & $\mathrm{x}$ & \\
\hline Des dobramentos da estratégia (aus ência, inadequação) & & $\mathrm{x}$ & & $\mathrm{x}$ & & & $\mathrm{x}$ & $\mathrm{x}$ \\
\hline Gestão da estratégia ad-hoc & & $\mathrm{x}$ & & & & & & \\
\hline Turnover das lideranças & & & $\mathrm{x}$ & & & & & \\
\hline Tempo de Implementação (superior ao prazo) & & & $\mathrm{x}$ & & & & & \\
\hline Sistemas de Informação (inadequação) & & & $\mathrm{x}$ & & & & & \\
\hline Grandes mudanças no ambiente competitivo & & & $\mathrm{x}$ & & & & & \\
\hline Formulação ina de qua da (aus ência de lideres internos) & & & $\mathrm{x}$ & & & & & \\
\hline Incentivos/punições (ausência) & $\mathrm{x}$ & & & & & & $\mathrm{x}$ & \\
\hline
\end{tabular}

Quadro 1 - Barreiras do processo de implementação da estratégia

Fonte: Elaborado pelos autores 
As Contribuições do Empreendedorismo Corporativo à Implementação de Estratégias

A comunicação da estratégia de forma ineficaz ou inadequada constitui uma barreira amplamente difundida na literatura em pesquisas organizacionais (MANKINS, STEELE, 2005; ZAGOTTA, ROBINSON, 2002; ZAGOTTA, ROBINSON, 2002; DEVLIN, 1989; ATKINSON, 2006; HREBINIAK, 2005; BEER, EISENSTAT, 2000). Deficiências neste fator impedem, principalmente, que os mecanismos ou métodos para a implementação das estratégias funcionem adequadamente. $O$ ruído na comunicação entre pessoas ou unidades organizacionais perturba na consecução dos objetivos e planos estratégicos.

A ausência de sistemas de monitoramento, ou ainda, sua deficiência ou inadequação, constituemse em um dos empecilhos também significativos à implementação (MANKINS, STEELE, 2005; ZAGOTTA, ROBINSON, 2002; DEVLIN, 1989; KAPLAN, NORTON, 1997; ATKINSON, 2006; HREBINIAK, 2005). Os sistemas gerenciais tradicionais são indicados como a causa da incoerência entre a formulação e implementação da estratégia e, com indicadores desajustados, impedem um eficiente monitoramento do progresso das ações e dos resultados vinculados á estratégia.

O dimensionamento incorreto das necessidades de recursos para a colocação da estratégia em ação pode acarretar na escolha por estratégias, muitas vezes, inviáveis, considerando a disponibilidade e adequação desses recursos. A alocação de maneira inadequada ainda pode impactar, negativamente, no desenvolvimento de programas de ação e iniciativas estratégicas (MANKINS, STEELE, 2005; DEVLIN, 1989; KAPLAN, NORTON, 1997; KIM, MAUBORGNE, 2005; HREBINIAK, 2005).

Outra barreira significativa refere-se à cultura organizacional (MANKINS, STEELE, 2005; DEVLIN, 1989; KIM, MAUBORGNE, 2005; HREBINIAK, 2005). Recente estudo com bases quantitativas, promovido por Ahmadi et. Al. (2012), indicaram uma relação significativamente positiva entre os tipos de culturas organizacionais e o processo de implementação das estratégias. Implementar novas estratégias implica em implementar mudanças e conflitos com o sistema de poder e status quo da organização podem emergir. Grupos de interesse, normalmente informais, surgem como oposição bloqueando a estratégia.

A falta de sincronização entre as prioridades e ações que remetem à competência e estrutura organizacional e os requerimentos da estratégia, denota um desajuste no alinhamento (MANKINS, STEELE, 2005; DEVLIN, 1989; KIM, MAUBORGNE, 2005; BEER, EISENSTAT, 2000). Por consequência, todos os esforços da organização para a execução de uma nova estratégia tendem a ser insuficientes, não pela falta ou indisponibilidade.
Uma próxima barreira com significativo destaque refere-se a não vinculação ou quantificação da visão e objetivos (ZAGOTTA, ROBINSON, 2002; KAPLAN, NORTON, 1997; ATKINSON, 2006; HREBINIAK, 2005). Esta dificuldade vem à tona quando os líderes do processo de implementação não conseguem traduzir a estratégia de forma compreensível e factível, não estabelecendo vínculos com as metas para departamentos, equipes e indivíduos.

Ainda, a frágil coordenação das ações de execução da estratégia, principalmente das lideranças, constitui-se em mais um obstáculo (MANKINS, STEELE, 2005; ATKINSON, 2006; BEER, EISENSTAT, 2000). Os movimentos organizacionais rumo à implementação requerem ações executadas em tempo adequado e sincronizados com outras áreas, departamentos e equipes, de modo que, a organização como um sistema, funcione satisfatoriamente.

A falta de desdobramento da estratégia por toda organização, com a atribuição das responsabilidades entre as pessoas e os objetivos das unidades de negócio, ou ainda, sua inadequação que impossibilita o pleno entendimento, emerge como uma barreira (ZAGOTTA, ROBINSON, 2002; KAPLAN, NORTON, 1997; HREBINIAK, 2005; BEER, EISENSTAT, 2000). Muitas vezes, os planos formulados pela equipe de planejamento são genéricos demais o que impede que as estratégias alcancem o nível operacional.

Por fim, ainda que citadas em menor escala na literatura pesquisada, outras barreiras ao processo de implementação da estratégia podem ser observadas: Falta de clareza nas definições de accountability pela execução das ações (MANKINS, STEELE, 2005); Gestão da estratégia como um evento ad-hoc, desvinculada da rotina da organização (ZAGOTTA, ROBINSON, 2002); Turnover nas lideranças responsáveis pela formulação e execução da estratégia, tempo de implementação da estratégia superior aos prazos programados e estimados, sistema de informação e reporte inadequados, grandes mudanças não esperadas no ambiente competitivo, não envolvimento de pessoas chave e líderes internos de opinião nas etapas de formulação da estratégia (DEVLIN, 1989); Ausência de mecanismos de incentivos ou punições para o processo de implementação (MANKINS, STEELE, 2005; HREBINIAK, 2005).

\section{O EMPREENDEDORISMO CORPORATIVO COMO UMA ALTERNATIVA AOS PROBLEMAS DA IMPLEMENTAÇÃO DA ESTRATÉGIA}


As Contribuições do Empreendedorismo Corporativo à Implementação de Estratégias

O Empreendedorismo corporativo pode ser conceituado como o empreendedorismo dentro de empresas existentes (ANTONCIC, HISRICH, 2001). É um empregado dotado de características empreendedoras e constitui um modelo de trabalhador desejável no contexto da organização, uma vez que adota uma postura semelhante àquela do dono do negócio. Com suas raízes fixadas no empreendedorismo, o tema ganhou maior notoriedade no contexto atual pois norteia as empresas para um caminho em busca de maior agilidade e flexibilidade, ou seja, por maior competitividade (LANA, TEIXEIRA, SILVA, 2011).

De forma mais incisiva, a prática do empreendedorismo corporativo tem o intuito de aumentar a rentabilidade da empresa (ZAHRA, 1991). Para isso, as organizações necessitam criar mecanismos e mentalidades capazes de apoiar e reconhecer iniciativas de inovação e empreendedorismo em seus ambientes de negócios (FERRAZ et al., 2008). Uma característica distinta das empresas empreendedoras, por exemplo, é sua capacidade de reconhecer e perseguir oportunidades bem à frente dos seus concorrentes, e fazê-lo apesar dos recursos limitados (SHANE, VENKATARAMAN, 2000). Uma organização muito empreendedora tende a ser mais competitiva do que uma organização pouco empreendedora, tendo assim, maior probabilidade de obter êxito em seu segmento de atuação (LANA, TEIXEIRA, SILVA , 2011). É válido destacar, que o escopo do empreendedorismo corporativo é cada vez mais amplo, e organizações, até então, reconhecidamente pouco empreendedoras, estão mudando sua forma de atuar promovendo um ambiente voltado à inovação (TIPURIĆ, 2013).

\subsection{CARACTERÍSTICAS DO EMPREENDEDOR CORPORATIVO}

A partir da literatura pesquisada, as várias características que descrevem o perfil do empreendedor corporativo foram alocadas em clusters, permitindo uma organização das informações de forma que o entendimento do que foi pesquisado torne-se mais inteligível. São 8 os grupos de características gerados que, ao final, dão origem a um framework.

Oportunidades: Detém habilidade pessoal para reconhecer oportunidades (CHANDLER, JANSEN, 1992). O empreendedor corporativo pode ser qualificado como uma pessoa que imagina e desenvolve visões e auxilia no processo de busca de novas oportunidades, sejam elas atuais ou futuras (FILION, 1999A, 1999B; ANTONCIC \& HISRICH, 2001; KURATKO ET AL., 2005). Desenvolve uma orientação, ou visão, que indica o que deverá ser feito aproveitando, até mesmo, situações incomuns, desenvolvendo visões emergentes e visões complementares (FILION, 2004). As atribuições do empreendedor corporativo não são restritas somente ao aspecto visionário, ele também desenvolve estratégias e até mesmo novas posturas competitivas (ANTONCIC, HISRICH, 2001). A esse profissional pode ser atribuído, também, a responsabilidade pelo que a literatura chama de coporate venturing, que consiste no desenvolvimento de novos negócios em corporações já existentes (DORNELAS, 2008; KURATKO, 2005, 2014; YIU, LAU, 2008).

Persistência: Apesar das profundas transformações socioeconômicas ocorridas desde que Schumpeter escreveu "A Teoria do Desenvolvimento Econômico", uma dimensão fundamental da ação empreendedora permanece: resistência e conflito institucional. Possui enorme força em realizar o novo, enfrenta resistências de competidores, de agentes em que precisa estabelecer cooperação e dos próprios consumidores (MARTES, 2010). A capacidade de manter-se focado para o alcance dos objetivos, com um locus interno controlado, também é uma de suas características (BOLTON; THOMPSON, 2000). Além disso, se opõe e enfrenta resistência ao ambiente social contra os impedimentos legais e políticos do quadro institucional (MARTES, 2010). É capaz de sustentar a continuidade da execução da ação que inicia (FILION, 2004).

Eficiência: Esse profissional que empreende dentro das organizações pode ser qualificado como proativo e propenso ao risco. Considerando que o pioneirismo pode consistir em vantagens competitivas para a organização, empreender corporativamente significa ir a procura de ocasiões favoráveis de mercado ao invés da espera passiva e da resposta aos concorrentes (ZAHRA, GARVIS, 2000). Uma pessoa imbuída desse perfil é dotada de capacidade para criação de riqueza através da combinação de recursos já existentes na empresa (YIU, LAU, 2008). Possui capacidade adaptativa, o que a faz lidar melhor com as mudanças no ambiente (SEXTON; BOWMAN, 1985). Também, possui habilidade e até preferência pela operacionalização de atividades, motivado, talvez, pela necessidade de realização (HULL, BOSLEY, UDELL, 1980). Ele não apenas desenvolve visões, é proativo e propenso ao risco, mas é, em sua essência, um realizador (FILION, 2004; ZAHRA, COVINS, 1995, 2000). Como líder organizacional, promove a incorporação de níveis adequados de risco e tolerância a falhas (KURATKO, 2014).

Informações: A pessoa que empreende, não apenas no contexto organizacional, não se limita aos seus próprios talentos (intuição, criatividade e intelectualidade), levando ao ato de empreender recursos interdisciplinares adquiridos com a experiência e o conhecimento (DRUCKER, 1987). 
Possui necessidade de atualização permanente (LEITE, 2000). Busca novos conhecimentos e procura saber como as coisas funcionam e são feitas, para fazê-las melhor (KIESSLING, RICHEY, 2004). Ainda, com sua constante inquietação na busca de novos conhecimentos, pode reduzir os custos da aprendizagem organizacional (POSTREL, 2002; FICHMAN E KEMERER, 1997; BOJICA E FUENTES, 2012).

Planejamento: O líder com este perfil escapa ao enquadramento usual dos problemas e soluções já testadas, o que o leva a planejar e racionalizar sua ação persistentemente, possuindo grande capacidade de liderança para instituir a inovação (MARTES, 2010). Desempenha o processo de renovação estratégica, que envolve a revitalização de operações através de alterações do escopo do negócio, da abordagem competitiva e na construção ou aquisição de novas capacidades (YIU, LAU, 2008). Como um planejador, possui habilidade de executar mas também de controlar, permitindo uma condição mais segura no processo de tomada de decisão (DORNELAS, 2001). Possui forte habilidade de gestão com altos níveis de responsabilidade e autoridade (E. H. SCHEIN, 1987). $\mathrm{O}$ empreendedor, visto como um fenômeno integrado ao contexto socioeconômico da empresa, contribui para o delineamento de perspectivas estratégicas da organização (BOJICA, FUENTES, 2012).

Metas: Uma das principais características do empreendedor está na necessidade em atingir seus alvos com dedicação e a disciplina de um estrategista militar (MCCLELLAND, 1972). Ele age racionalmente movido pelo desejo de conquista, de luta por um objetivo (MARTES, 2010). Além de determinado e autoconfiante, possui senso de direção e é orientado por metas (TIMMONS, 1978).

Controle: Detém capacidade para o estabelecimento de controles (WELCH \& WHITE, 1981). Inserido no contexto das organizações, esse profissional é considerado inovador, alinhado com os objetivos da empresa e se preocupa constantemente em implementar melhorias nos processos (LANA,
TEIXEIRA, SILVA J, 2011). A preferência pela execução das tarefas e locus de controle que possui, o auxiliam neste processo (HULL, BOSLEY, \& UDELL 1980).

Persuasão: O empreendedor corporativo é uma pessoa que dispõe de um alto nível de compromisso com o que faz (FILION, 2004). Cria um clima ou atmosfera na qual as pessoas são incentivadas a fazer mais do que o mínimo exigido, criando um comprometimento com o seu trabalho como se a empresa a eles pertencesse. Comprometendo-se, os indivíduos se apropriam de seus papéis, aprendem e continuam evoluindo dentro da organização. Todos sentem-se parte de um processo e são imbuídos de um sentimento de superação para ajudar a realizar a visão (FILION, 2004). Promovem a implementação de processos e infraestruturas que permitem a colaboração (participação), com políticas de incentivos claros que oferecem recompensas apropriadas para a geração de ideias (KOETZIER, ALON, 2013). Possui habilidade para claramente comunicar metas (HOFER \& SANDBERG, 1987). Em suas habilidades interpessoais, é capaz de delegar e atuar como gestor de relações com o cliente e empregados (IBRAHIM \& GOODWIN, 1986).

A partir do agrupamento dessas características, foi desenvolvido um framework das características do empreendedor corporativo. $\mathrm{O}$ resultado visual apresentado na Figura 1 liga os clusters às características singulares sintetizadas.

Considerando o objetivo proposto do trabalho em buscar soluções aos problemas de implementação da estratégia, tendo o empreendedorismo corporativo como essa possível solução, são apresentadas a seguir as proposições teóricas. A fim de expô-las de forma mais clara possível, as proposições são precedidas das barreiras à implementação encontradas na literatura, anteriormente definidas. Por último é apresentado a Quadro 2, que resume pontualmente, como as características do empreendedor impactam nas barreiras à implementação. 
As Contribuições do Empreendedorismo Corporativo à Implementação de Estratégias

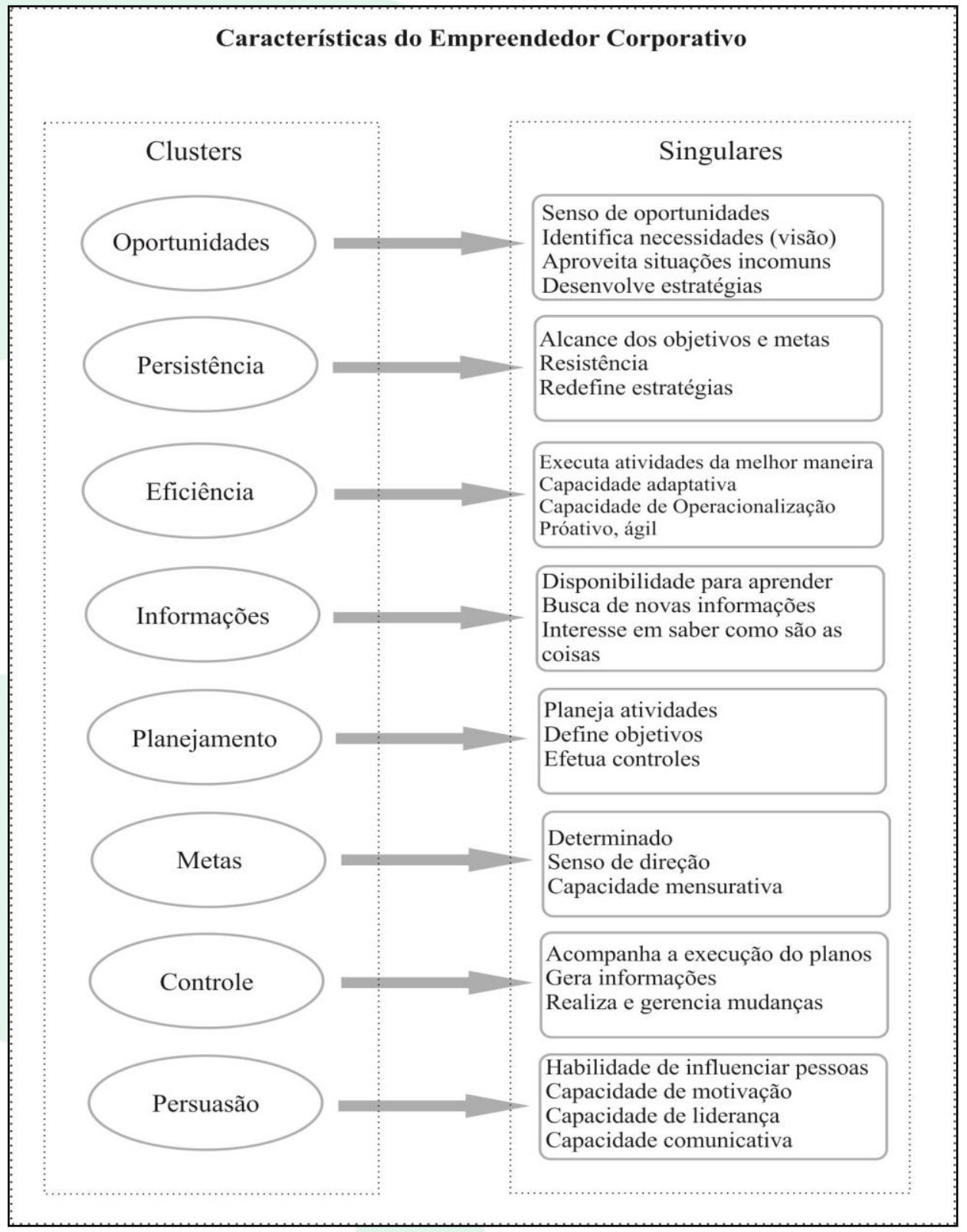

Figura 1 - Características do empreendedor corporativo

Fonte: Elaborado pelos autores

\subsection{IMPACTOS DO EMPREENDEDORISMO CORPORATIVO PARA A IMPLEMENTAÇÃO DE ESTRATÉGIAS}

Barreira 1: Desdobramentos da estratégia: ausência ou tradução inadequada da estratégia e da visão

Os clusters de características Oportunidades, Eficiência e Metas do empreendedor corporativo podem auxiliar a organização a superar a barreira de desdobramentos da estratégia. $\mathrm{O}$ empreendedor, em seu perfil, naturalmente, desenvolve uma orientação ou visão que indica o que deverá ser feito. Possui um nível de percepção que o possibilita identificar as necessidades que o processo de implementação demanda. Como implementar novas estratégias significa, também, implementar mudanças, o empreendedor corporativo é dotado de uma capacidade adaptativa que o faz lidar melhor com as mudanças no ambiente. Detém, ainda, a capacidade operacionalização, estabelecendo, dessa forma, os desdobramentos para que as estratégias, excessivamente genéricas, alcancem o nível operacional das atividades. Corroborando ainda para a superação desta barreira, a pessoa com este perfil, além de determinado, possui um senso de direção que o auxilia no estabelecimento de metas e objetivos quantificáveis para o processo. 
As Contribuições do Empreendedorismo Corporativo à Implementação de Estratégias

Proposição 1: Característica visionária, adaptativa e comunicativa do empreendedor contribui para uma tradução adequada da estratégia e da visão

Barreira 2: Comunicação inadequada e ineficaz da estratégia

À barreira de comunicação da estratégia, o cluster Persuasão pode oferecer uma alternativa. Pela liderança natural da pessoa com este perfil, diferentemente do que processos atuais sugerem, a característica comunicativa obtém efeito pelo alto nível de compromisso e comprometimento exteriorizado para com a organização. A evidente habilidade para comunicação de novas estratégias e metas vem ao encontro de suas habilidades interpessoais como gestor de relações em seu ambiente. Não obstante à comunicação da estratégia, o sentimento de superação é propagado na equipe, o que contribui para o alcance das metas e objetivos propostos.

Proposição 2: Característica persuasiva do empreendedor corporativo contribui para reduzir os problemas de comunicação inadequada e ineficaz da estratégia

Barreira 3: Lideranças: falta de comprometimento e atuação

Em relação à barreira da falta de comprometimento e atuação das lideranças, os clusters de características Metas e Persuasão do empreendedor corporativo podem contribuir para resolução do problema. A necessidade em atingir seus alvos, com que a literatura chama de dedicação e disciplina de um estrategista militar, faz com que o líder com este perfil tenha comprometimento e, por consequência, a atuação necessária que o processo de implementação de estratégias exige. Com seu modo racional de agir e seu desejo de conquista, ele se apropria dos objetivos organizacionais quanto às novas estratégias e sustenta a continuidade da execução até que o processo obtenha fim. Líderes organizacionais com perfil empreendedor possuem a capacidade para criar um clima ou uma atmosfera no qual o processo de implementação tornase um objetivo possível de ser alcançado e superado. As novas estratégias adotas pela organização, muitas vezes, carregadas de incerteza e imprevisibilidade, encontram nesse perfil de profissional o alento necessário para que sejam efetivamente implementadas. O envolvimento e o comprometimento pelo novo são virtudes que fazem parte e estão implícitas em sua trajetória profissional nas empresas.

Proposição 3: O empreendedor corporativo como um mobilizador de equipes e líder comprometido com as ações da Implementação da estratégia

Barreira 4: Grandes mudanças no ambiente: incapacidade de gerenciamento
O cluster de características Controle pode fornecer uma saída à barreira da incapacidade de gerenciamento de grandes mudanças. O empreendedorismo corporativo, como já mencionado, tem suas raízes fixadas no empreendedorismo e como sugere Schumpeter (1982, 1985), o tema subjacente também tem forte aptidão para lidar com mudanças. Ao empreendedor atribuiu o termo destruição criativa, considerando revolucionária a atuação empreendedora sobre a economia do país. Preconizava que o perfil empreendedor sustentava-se na inovação e na renovação tecnológica, estimulando o progresso econômico. Definia que empreender é promover uma ruptura, ou seja, gerar mudanças, inovando para criar uma transformação radical onde o empreendedor atua. Como já mencionado, implementar novas estratégias significa implementar mudanças, e a liderança do empreendedor corporativo pode contribuir de maneira decisiva para que este processo obtenha resultados satisfatórios. Sendo considerado um profissional inovador e alinhado com os objetivos da organização, este processo de implementação, que tem em sua finalidade melhorar o desempenho organizacional para o alcance de determinado objetivo, encontra no empreendedor um agente de mudanças. Sua capacidade em lidar com o novo é observado pelos membros da equipe como um parâmetro de conduta, característica aliada à sua reconhecida habilidade de mobilização e engajamento das pessoas.

Proposição 4: O empreendedor corporativo como um líder capaz de gerenciar grandes mudanças

Barreira 5: Cultura Organizacional: sistemas de poder e status quo

A barreira da implementação da estratégia referente à cultura organizacional encontra nos clusters de características Persuasão e Persistência do empreendedor uma potencial solução. Uma dimensão, preconizada por Schumpeter, da ação empreendedora pode auxiliar no desbaratamento do obstáculo citado: resistência e conflito institucional. Se empreender é promover ruptura, pode significar também, romper com a cultura predominante de uma instituição. Convencido de que uma nova estratégia é adequada e de que trará benefícios à empresa, possui prédisposição em encarar conflitos, resistindo tanto quanto for necessário. Se inevitável, em sua essência, possui propensão a se opor ao ambiente social contra os impedimentos legais e políticos do quadro institucional que impedem a implementação de mudanças. Somente desistirá de sua postura se for persuadido do contrário, ou então, tal comportamento poderá acarretar em dificuldades de continuidade na instituição. Como possui capacidade de sustentar suas ações de execução, o bloqueio à estratégia por grupos informais pode ser destituído pelas características persuasivas do empreendedor, que não apenas mobiliza e engaja equipes em favor do novo, como também interfere positivamente na cultura. Essa interferência caminha 
As Contribuições do Empreendedorismo Corporativo à Implementação de Estratégias

em prol da criação de programas que promovem a cultura empreendedora da empresa, estabelecendo parâmetros para a participação dos agentes organizacionais (KURATKO, 2014).

Proposição 5: O empreendedor corporativo como líder transformador da cultura organizacional

Barreira 6: Lideranças: falta de habilidade e competência inadequada

Para a barreira relativa à falta de habilidade e competência inadequada das lideranças, o conjunto de características Informações, Eficiência e Planejamento propõe soluções. O líder organizacional que é empreendedor sente a necessidade de atualização permanente, busca novos conhecimentos e procura saber como as coisas funcionam e são feitas, com o intuito de fazê-las melhor, o que, em tese, supriria a demanda de habilidades e competências necessárias à implementação. Estudos mostram que o efeito positivo da aquisição de conhecimento, além do auxílio na implementação da estratégia, está correlacionado positivamente com o desempenho das empresas (BOJICA, FUENTES 2012). É um profissional que procura, na execução das atividades, efetuá-las da melhor maneira propondo novas soluções, o que o leva a planejar e racionalizar suas ações persistentemente. $\mathrm{O}$ agente empreendedor pode ser considerado um líder orientador para o dimensionamento de recursos necessários à implementação de estratégias. Para este fim, o planejamento e a racionalização das atividades e processos contempla o comprometimento de recursos organizacionais, sejam humanos, financeiros e, até mesmo, produtivos. Esta atribuição só é possível devido ao conhecimento global adquirido que o empreendedor corporativo tem do negócio e da empresa. Ainda, detém habilidade que pode direcionar a organização para aquisição de novas capacidades e recursos necessários à implementação de estratégias e ao alcance dos objetivos.

Proposição 6: O empreendedor corporativo como um líder capaz e hábil para a articulação das ações estratégicas

Após a apresentação das proposições, a Quadro 2 elucida sucintamente como as características do empreendedor corporativo se conectam as barreiras da implementação. Os clusters, muitas vezes combinados, auxiliam na resolução de mais de uma barreira que, por sua vez, dão origem às proposições teóricas.

\begin{tabular}{|c|c|c|c|c|c|c|}
\hline $\begin{array}{ll}\begin{array}{l}\text { Clusters de } \\
\text { Características }\end{array} & \text { Barreiras } \\
\end{array}$ & Barreira 1 & Barreira 2 & Barreira 3 & Barreira 4 & Barreira 5 & Barreira 6 \\
\hline Oportunidades & $\mathrm{X}$ & & & & & \\
\hline Persistência & & & & & $\bar{X}$ & \\
\hline Eficiência & $\mathrm{X}$ & & & & & $\mathrm{X}$ \\
\hline Informações & & 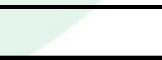 & & & & $\bar{X}$ \\
\hline Planejamento & & 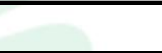 & & & & $\mathrm{X}$ \\
\hline Metas & $\mathrm{X}$ & 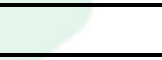 & $\mathrm{X}$ & & & \\
\hline Controle & & - & & $\mathrm{X}$ & & \\
\hline Persuasão & & $X$ & $\bar{X}$ & & $\mathrm{X}$ & \\
\hline
\end{tabular}

Quadro 2 - Características do empreendedor corporativo e as barreiras à implementação da estratégia Fonte: Elaborado pelos autores

\section{CONCLUSÕES}

O intuito deste ensaio teórico, que teve um caráter inovador, foi estabelecer conexão entre dois dos temas mais tratados do campo da estratégia, sustentando, com embasamentos teóricos, soluções aos problemas da implementação da estratégia pelo emprego do empreendedorismo corporativo.

Pesquisas recentes apontam, como um dos principais desafios impostos aos gestores e estudiosos em administração, a implementação da estratégia. O êxito neste processo não tem sido superior a $20 \%$ em relação às estratégias formuladas que são efetivamente executadas. A dificuldade em obter, na prática, os resultados delineados no processo de definição de objetivos e estratégias, aponta para a existência de um gap entre o que se planeja e o que efetivamente se executa. Autores com trabalhos na área destacam que, cada vez mais, a diferença entre uma empresa e sua concorrente, reside na habilidade de executar.

Para as barreiras da implementação, as proposições sugerem o empreendedor corporativo como uma alternativa viável. Ele é definido como um empregado dotado de características empreendedoras e constitui um modelo de trabalhador desejável no contexto da organização, uma vez que adota uma postura semelhante àquela do dono do negócio. As proposições o apontam como um líder visionário, 
As Contribuições do Empreendedorismo Corporativo à Implementação de Estratégias

tradutor e comunicador da estratégia, comprometido com as ações da implementação, mobilizador de equipes em favor do novo, capaz de gerenciar grandes mudanças, transformador da cultura organizacional e líder hábil para articulação de ações da estratégia. Recentes estudos demonstraram, ainda, que um alto grau de empreendedorismo está associado positivamente com o desempenho da empresa (BOJICA, FUENTES, 2012).

Entre algumas características do perfil deste profissional que sustentam as proposições, está a de que ele escapa ao enquadramento usual dos problemas e soluções já testados, planejando e racionalizando suas ações. É uma pessoa que não se limita aos seus próprios talentos, conduzindo ao ato de empreender recursos interdisciplinares adquiridos com a experiência e o conhecimento. Carrega consigo a dimensão da resistência e conflito organizacional, promovendo rupturas no ambiente social e legal da instituição em prol do estabelecimento de uma nova cultura. O novo clima ou atmosfera instalada pelo empreendedor corporativo incentiva as pessoas a fazer mais do que o mínimo exigido, criando um senso comum de comprometimento, alinhando os objetivos pessoais aos novos objetivos organizacionais. Por fim, é um líder proativo e propenso ao risco e que desenvolve visões emergentes e complementares, auxiliando a organização na busca de novas oportunidades.

Não pretende-se afirmar que todos os problemas relacionados à implementação da estratégia encontram no empreendedorismo corporativo a solução. Apenas conclui-se, suportado pela teoria, de que ações organizacionais em prol do desenvolvimento de uma cultura empreendedora em seu ambiente interno, pode facilitar o estabelecimento do novo, da mudança, da transformação organizacional em nome de uma nova postura competitiva exigida pelo ambiente. A atuação do empreendedor corporativo, ainda que limitada por alguns impedimentos legais, pode capacitar a organização de alguns atributos desejáveis neste novo contexto, como flexibilidade, agilidade, e rápida implementação de ações estratégicas.

Considerando que este estudo é um ensaio teórico, abre-se a possibilidade para futuros trabalhos, a investigação das proposições sugeridas através de pesquisas empíricas. Ou seja, a partir de evidências observadas na prática, o tema poderá sofrer mudanças, acréscimos, ou mesmo, uma alteração profunda de seu entendimento. Como perspectiva para novas pesquisas, os seguintes questionamentos poderiam ser objetos de estudo: (I) $\mathrm{O}$ empreendedorismo corporativo, na prática, auxilia a organização na implementação de suas estratégias? (II) Um resultado satisfatório neste processo tem haver com o perfil mais ou menos empreendedor da organização? (III) Como capacitar as empresas para serem mais empreendedoras? (IV)
Como tornar ou obter colaboradores que possuam o perfil do empreendedor corporativo?

\section{REFERÊNCIAS}

Ahmadi, S.; Salamzadeh, Y.; DAraei, M.; AKBARI, J. Relationship between Organizational Culture and Strategy Implementation: Typologies and Dimensions. Global Business and Management Research: An International Journal. Vol. 4, No. 3 \& 4, 2012 .

Antoncic, B.; Hisrich, R. D. Intrapreneurship: construct refinement and cross cultural validation. Journal of Business Venturing, EUA, 16, 495-527, 2001

Atkinson, H.. Strategy Implementation: a role for the balanced scorecard? Management Decision, 44 (10), 1441-1460, 2006

Beer, M.; Eisenstat, R. A. The Silent Killers of Strategy Implementation and Learning. Sloan Management Review, Summer, 2000.

Bojica, A. M.; Fuentes, M. M. Knowledge acquisition and corporate entrepreneurship: Insights from Spanish SMEs in the ICT sector. Journal of World Business, 47, 397-408, 2012.

Bolton, B., \& Thompson, J. Entrepreneurs talent, temperament, technique. Oxford: butterworth Heinemann, 2000

Bower, J. L. Solving the problems of business planning. Journal of business strategy, 2 (3), 1982.

Bossidy, L.; Charan, R. Execução - a disciplina para atingir resultados. Rio de Janeiro, Campus, 2004.

Bossidy, L.; Charan, R.. Confronting Reality doing what matters to get things right. New York, Crown Business, 2004

Campbell, A.; Alexander, M. What's wrong with strategy? Harvard Business Review, 42-51, 1997.

Chandler, G. N.; Jansen, E. The founder's selfassessed competence and venture performance. Journal of Business Venturing, 7 (3), 233-236, 1992.

Devlin. G. How to Implement a Winning Strategy. European Management Journal, 7 (3), 1989 
As Contribuições do Empreendedorismo Corporativo à Implementação de Estratégias

Dornelas, J. C. A. Empreendedorismo Corporativo, 2 ed. Rio de Janeiro: Elsevier, 2008.

Drucker, P. F. Inovação e espírito empreendedor. São Paulo: Pioneira, 1987.

Ferraz, S. F. F.; Costa, I. B.; Duarte, M. F; Oliveira, A. C. M.; Leocádio, L. Práticas e modelo intraempreendedor em uma grande indústria têxtil brasileira. Congresso Nacional de Excelência em Gestão. Niterói , RJ, 3, 2008.

Ferreira et. Al. Desde os Primórdios até hoje em dia: Será que o Empreendedor ainda faz o que Schumpeter dizia? Evolução das Características Empreendedoras de 1983 a 2010. Anais do Encontro Nacional da Associação Nacional de PósGraduação e Pesquisa em Administração, Rio de Janeiro, Brasil, 35, 2011.

Faull, N.; Fleming P. Insights from research - Turning intentions into outcomes: a quick scorecard to guide implementation. Measuring Business Excellence, 2005.

Filion, L. J. Entendendo os Intraempreendedores como Visionistas. Revista de Negócios, 9 (2), Blumenau, abril/junho, 2004.

Gil, A. C. Como elaborar projetos de pesquisa. São Paulo: Atlas, 1991.

Godoy, A. S. Introdução à pesquisa qualitativa e suas possibilidades. Revista de Administração de Empresas. São Paulo: 35 (2), 57-63, abril, 1995.

Guedes, S. A. A carreira do empreendedor. Dissertação de Mestrado, Universidade de São Paulo, São Paulo, SP, Brasil, 2009.

Hambrick, D. C.; Cannella Jr. A. A. Strategy implementation as substance and selling. Academy of Management Executive, 3 (4), 278-285, 1989.

Hofer, C. W.; Sandberg, W. R. Improving new venture performance: Some guidelines for success. American Journal of Small Business, 12(1), 11-25, 1987.

Hornsby, J. B.; Kuratko, D. F.; Zahra, S. A. Middle managers' perception of the internal environment for corporate entrepreneurship: Assessing a measurement scale. Journal of Business Venturing, 17,2002.
Hrebiniak, L. G.. Making Strategy Work - Leading effective execution and change. Wharton School Publisher, 2005.

Hull, D. L., Bosley, J. J., \& Udell, G. G. Reviewing the heffalump: identifying potential entrepreneurs by personality characteristics. Journal of Small Business Management, 18, p. 11-18, 1980.

Ibrahim, A. B.; Goodwin, J. R; Perceived causes of success in small business. American Journal of Small Business, 12(1), 41-50, 1986.

Johnson,L.K. "Execute your strategy-without killingit". Harvard Management Update, December, pp. 3-5, 2004.

Kaplan, R. S., Norton, D. P. A Estratégia em Ação: Balanced Scorecard. Rio de Janeiro, Editora Campus, 1997.

Kenny, J. Strategy and the learning organization: a maturity model for the formation of strategy. The Learning Organization, 13 (4), 353-368, 2006.

Kiessling, T. S.; Richey, R. G. Examining the theoretical inspirations of a management guru: Peter F. Drucker and the Austrian School of Economics. Management Decision,42 (10), 12691283, 2004.

Kim, C.; Mauborgne, R. A Estratégia do Oceano Azul - Como criar novos mercados e tornar a concorrência irrelevante. Rio de Janeiro, Campus-Elsevier, 2005.

Kirzner, I. M. Competição e atividade empresarial. Rio de janeiro: Instituto Liberal, 1986

Koetzier W.; Alon, A. Why "Low Risk" Innovation Is Costly: Overcoming the Perils of Renovation and Invention. Accenture, 2013.

Kuratko, D. F.; Ireland, D. F.; Covin, J. G.; Hornsby, J. S. A model of middle-level managers' entrepreneurial behavior. Entrepreneurship Theory and Practice, 29 (5), 699-716, 2005b.

Kuratko , D F.; Covin, J. G.; Hornsby, J. S. Why implementing corporate innovation is so difficult? Business Horizons, vol 57, 647-655, 2014.

Kuratko, D. F., Hornsby, J. B., \& Bishop, J. W. Managers' corporate entrepreneurial actions and job satisfaction. International and Entrepreneurship Jounal, 1 (3), 275-291, 2005a. 
Lana B.,Teixeira L.; SILVA J. Intraempreendedorismo: uma análise das percepções do gestor sobre o perfil de seus funcionários. Anais do Encontro Nacional da Associação Nacional de Pós-Graduação e Pesquisa em Administração, Rio de Janeiro, Brasil, 35, 2011.

Leite, E. O fenômeno do empreendedorismo: criando riquezas. Recife: Bagaço, 2000.

Mair, J. Entrepreneurial Behaviour in a large traditional firm: Exploring key drivers. Research paper, 466, Jun, 2002a.

Mankins M. C.; Steele, R. Turning Great Strategy into Great Performance. Harvard Business Review, jul/aug, 2005.

Mariotto, F. B. Mobilizando Estratégias Emergentes. RAE, 43(2), 2003.

Martes, A. C. B. Weber e Schumpeter: A ação econômica do empreendedor. Revista de Economia Política, 30 (2), abril/junho, 2010.

Mcclelland, D. C. A sociedade competitiva - realização e progresso Social. Rio de Janeiro: Expressão e Cultura, 1972.

Mintzberg, H. Patterns in strategy formation. Management Science, 24 (9) 934-948, 1978.

Mintzberg, H.; WATERS, J. A. Of strategies, deliberate and emergent. Strategic Management Journal, 6, 257-272, Jul/Sep, 1985.

Mintzberg, H.. The fall and rise of strategic planning. Harvard Business Review, 107-114, Jan./Feb, 1994.

Mintzberg, H. ET AL. Safári de estratégia: um roteiro pela selva do planejamento estratégico. Porto Alegre: Bookman, 2000.

Nohria, N., W. Joyce, and B. Roberson.. What really works. Harvard Business Review, 81 (7): 42-52, 2003.

Osborn, C. S. Systems for sustainable organizations: emergent strategies, interactive controls and semiformal information. Journal of Management Studies, 35 (4), 481-509, 1998.

Okumus, F. A framework to implement strategies in organizations. Management Decision,41 (9): 87182. 2003
Pella, D. A.; Sumarwan, U.; Daryanto, A.; Mada, K. G. Factors Affecting Poor Strategy Implementation. International Journal of Business, Vol. 15, No. 2, 183 - 204, 2013.

Saunders, M., R. Mann, AND R. Smith R.. Implementing strategic initiatives: A framework of leading practices. International Journal of Operations dan Production Management, 28 (11): 1095-1123, 2008.

Shane, S.; Venkataraman, S.. The promise of entrepreneurship as a field of research. Academy of Management Review, 25, (1), 217-226, 2000.

Simons, R. Strategic orientation and top management attention to control systems. Strategic Management Journal, 12 (1), 49-62, 1991.

Schumpeter, J. A.. Capitalism, socialism, and democracy. New York: Harper, 1950.

Schumpeter, J.A. The theory of economic development. Oxford University Press, 1982.

Schumpeter, J. A. A Teoria do Desenvolvimento Econômico. Rio de Janeiro: Nova Cultural, 1985.

Sharma, P.; Chrisman, J. J. Toward a reconciliation of the definitional issues in the field of corporate entrepreneurship. Entrepreneurship Theory \& Practice, 23 (3),11-28, 1999.

Timmons, J. A. New venture creation: entrepreneurship for the 21st century. New York: Irwin/McGrawHill, 1999.

Tipurić, D.; Bakotić, D.; Lovrinčević, M. Multiple Stakeholder Orientation and Corporate Entrepreneurship: An Empirical Examination. 9th European Conference on Management Leadership and Governance, Austria, 2013.

Vilas BOAS, E. P.. Estudo das práticas de gestão empresarial de promoção do empreendedorismo corporativo: estudos de caso em empresas conhecidamente empreendedoras com atuação no brasil. Tese, Universidade de São Paulo, São Carlos, SP., 2009.

Weick, K. E. The social psychology of organizing. New York : McGraw-Hill, 1979.

Weick, K. E. Sensemaking in organizations. Thousand Oaks : Sage, 1995. 
Welch, J. A., \& White, J. F. A small business is not a little big business. Harvard Business Review,59 (4), 18-32, July/ Aug, 1981.

Yiu, D. W., \& Lau, C. M.. Corporate entrepreneurship as resource capital configurating in emerging market firms. Entrepreneurship Theory and practice, 32 (1), 3757, janeiro, 2008.

Zagotta, R.; Robinson, D. Keys To Successful Strategy Execution. The Journal of Business Strategy, jan/feb, 2002.
Zahra, S. A. Predictors and financial outcomes of corporate entrepreneurship: An exploratory study. Journal of BusinessVenturing, 6, 259-286, 1991.

Zahra, S. A., \& Covin, J. G. Contextual influences on the corporate entrepreneurship - Performance relationship: A longitudinal analysis. Journal of Business Venturing, 10, 43-58, 1995.

Zahra, S. A., \& Garvis, D. M. International corporate entrepreneurship and firm performance: The moderating effect of international environmental hostility. Journal of Business Venturing, 15, 469-492, 2000. 